Sonic Scope: New Approaches to Audiovisual Culture • Issue One

\title{
The Sounding Sewing \\ Machine: Re-Voicing \\ Gendered Media Histories
}

Lottie Sebes

Published on: Oct 06, 2020

DOI: 10.21428/66f840a4.985232e3

License: Creative Commons Attribution 4.0 International License (CC-BY 4.0). 


\section{ABSTRACT}

The Sounding Sowing Machine: Re-Voicing Gendered Media Histories Lottie Sebes, Berlin University of the Arts

This artistic research project examines nineteenth-and early twentieth-century vocal simulators, foot pedals and the sewing machine, as devices which demonstrate historical correlations between gender and technical media. It is argued that these devices have been predominantly operated by women in history, and that this trend has characterised their designs, functioning and social construction. The methodological approach taken in this project is underpinned by both feminist and media archaeological theoretical frameworks and takes place in both the traditional form of writing and in the artist's studio. Through sonic performance practice (documentation of which is provided throughout the paper), I re-appropriate aspects of these historical mechanisms and the gendered discourses surrounding them. By controlling these different technologies with my body on stage, I have created a dynamic woman-machine interface which questions and re-forges the possible uses and meanings of these tools.

\section{Introduction}

This artistic research project examines examples of nineteenth- and early twentieth-century technical media - vocal simulators, foot pedals and the sewing machine - as devices which demonstrate historical intersections of gender and technical media. Through a combination of studio-based performance practice and theoretical research, I use these gendered technologies as tools for feminist performance practice in order to explore and re-forge existing relationships between gender and technical media.

This applied methodology will be discussed in three sections. The first section briefly outlines the key critical frameworks and methodologies which inform my approach - feminist criticism, media archaeology and artistic research. Section two will focus on a range of nineteenth- and early twentiethcentury technologies, which were predominately operated by women. Cultural historian Hillel Schwartz notes that the range of new technologies developed in this period have had a fundamental impact on the development of a new human kinaesthetic in the nineteenth- and twentieth centuries, which significantly affected the ways in which we experience, understand and express ourselves through motion and movement. . In this project, I have explored such stories of entangled cultural and technological development, embracing the way "our bodies themselves have been configured into machinehood." 2 The technologies I explore include keyboard-and pedal-based mechanisms such as the piano, sewing machine and early typewriters, as well as 'talking machines' from the late 1930s, 
which were almost exclusively operated by women. Nineteenth- century talking mechanisms, including Joseph Faber's 'Euphonia' and Thomas Edison's talking dolls will also be examined. It will be argued that these technologies were inherently gendered by the conditions and design of their use. In section three, I will document and illuminate my studio-based research methodologies and practices, through which I discovered how these technologies and their gendered associations could be creatively reassembled through artistic means.

This studio research was due to culminate in a live performance in March 2020 entitled Veritas Ventriloquist. However, due to the COVID-19 crisis, the event was postponed and video documentation of the performance was created without a live audience (see Video 1). The translation of this performance into video had significant impacts upon the work and its reception. The editing process naturally affected the flow of the performance and direction of the spectator's attention. What has emerged incidentally from the limitations caused by COVID-19 is a work which navigates the boundaries of performance documentation and video art.

\section{Notes on Methodology}

The methodological approach taken in this artistic research project is underpinned by both feminist and media archaeological theoretical frameworks. Media archaeology is a heterogeneous discipline within the humanities, social sciences and media studies which seeks to understand new media 
through alternative, non-linear histories. These approaches often illuminate "hitherto unnoticed continuities and ruptures" such as obsolete, overlooked or imagined media. $\underline{3}$ The use of the term 'archaeology' in a media archaeological context stems from Michel Foucault's studies in the archaeologies of power and knowledge. $\underline{4}$ Foucault's archaeology is a methodology which looks at institutions, archives and documents to uncover why and how a statement, discourse or notion of history could be conceived and culturally maintained through them. The German media theorist Friedrich Kittler later applied a similar line of questioning to technical media and apparatuses, an investigation which strongly contributed to the development of media archaeology as a field. $\underline{5}$

This project concerns itself specifically with the ways in which gender relations have affected the development of media apparatuses, their use habits and cultural connotations, and how these constellations of gender and media have sustained themselves over time. It aims to bring these gendered aspects of technical media's history into conversation with contemporary media through creative performance practice. Hence, it subscribes to Erkki Huhtamo's description of media archaeology as "a critical practice that excavates media-cultural clues about neglected, misrepresented and/or suppressed aspects of both media's past(s) and their present and tries to bring these into a conversation with each other." $\underline{6}$ Media archaeological perspectives also often highlight the recursive, rather than linear nature of history; the way human myths and themes repeat themselves across time and context. - As an artist, I have the opportunity to not only identify these recurrences but to stage my own, through the intentional re-sampling of the archive of media history.

While many media archaeologists are varyingly interested in both the material and discursive aspects of media culture, some more radically aim to understand technical media exclusively on their own terms, as objects outside of "anthropomorphic" historical discourses, unclouded by "hermeneutic empathy." materialistic archaeologies with a focus on the techno-mathematical and scientific realities of signal transmission via hardware. Contrastingly, feminist approaches to histories of technology (while pluralistic and diverse) commonly focus on the social dimension of technologies' use in cultural context. Because of the materialist focus of some media archaeologists, and the supposed "mediaarcheological desire to be freed by machines from one's own subjectivity" feminist and media archaeological approaches could be seen to be in conflict. 9 However, my project adopts a transdisciplinary and more inclusive feminist media archaeological approach, as suggested by Lina Rahm and Jörgen Skågeby, which questions "how power, affects and practices are entangled with media materialities." 10

Donna Harraway's “A Cyborg Manifesto: Science, Technology and Socialist-Feminism in the Late 20th Century" provides a crucial critical framework for my approach to this research, as well as a 
bridge between feminist and post-humanist frameworks. $\underline{11}$ Harraway opposes the notion that women are in some way "closer to nature," calling for a feminist seizure of the tools of science and technology to instigate a feminist re-crafting of our bodies, myths and selves. She espouses "great riches for feminists in explicitly embracing the possibilities inherent in the breakdown of clean distinctions between organism and machine and similar distinctions structuring the Western self." $\underline{12}$ Inspired by Harraway's criticism, I will demonstrate and embrace the ways in which women have been historically enmeshed with a range of technical media materialities. These entanglements can be employed as critical tools for disrupting preconceptions surrounding gender and technology.

This inquiry is well suited to investigation through artistic research, as it takes place through practical and creative use of the same technical media which are its subject. Thus, by avoiding a process of translation into "the meta-language of words," it arguably fulfills one aspect of Ernst's call for a more radical media archaeology, in which the media archaeologist talks from within technology, elucidating messages and processes which come from within the technical mechanism itself. $\underline{13}$ This kind of tacit knowledge is implicit in artistic research, whereby thought can be understood, as Dieter Mersch claims, "as a practice, as acting with media, in media or through media." 14

The kinds of knowledge generated through artistic research practices can also comfortably encompass subjectivities. Mersch also attests that "art does not enter the slim space between truth and falsity ... Artistic work shows." $\underline{15}$ (emphasis in original). Some media archaeological approaches share this openness to imagination and speculation. $\underline{16}$ Ulrich Meurer proposes that while the petrified geological strata in the hard ground of the mountains may be the ideal location for an archaeologist, the beach is perhaps a stronger topographical metaphor for the media archaeologist. $\underline{17}$ On the beach, a historical fragment may be washed up on the sand at any time, without variable connection to other objects or exact epochs, engendered with a sense of chance, epiphany, coincidence - a story told in "degrees below truth." $\underline{18}$ It is this sense of speculation, of dream and fantasy which has driven this project and allowed it to adopt a multitude of theoretical lenses. In asking a series of open-ended questions, and by investigating through artistic practices, I have allowed myself to pursue numerous valid answers.

\section{Gendered histories: piano, sewing machine, typewriter, talking machine}

That particular machines have been largely operated by women in history is a phenomenon with layered and complex causes. The result, however, has been that gendered patterns of use have, over 
time, become inherently reflected in technological design. Historically, the gendered association between women and domestic labour often continued after many domestic tasks, such as sewing, were mechanised and industrialised. Women have also been a source of cheap labour, which historically led to their introduction into the workforce in positions where they commanded typewriters and telephone switchboards. Such service-based roles were also deemed particularly suitable for women because of the expectations placed on women to maintain a passive and dutiful demeanour, euphemistically described by AT\&T in 1938 as the "womanly virtues of devotion, helpfulness, sympathy [and] patience." $\underline{\text { 19 }}$ The technical abilities crafted by women using these machines also lead to their dominance in the use of other similarly designed tools. Hence, the social, cultural and economic reasons for gendered division of machine-use are also coupled with continuities and commonalities in the technical and aesthetic designs of machines. The foot pedal is an example of such a mechanism, common to several apparatuses including the sewing machine, typewriter and the piano.

In nineteenth-century Britain and the United States, learning to play the piano was a standard part of a middle class girl's education, while it was absent from standard male training. $\underline{20}$ While public, professional musicianship was still strongly dominated by men, playing the piano in a domestic context was commonly considered to be a good way for middle class women to attract a husband, and a

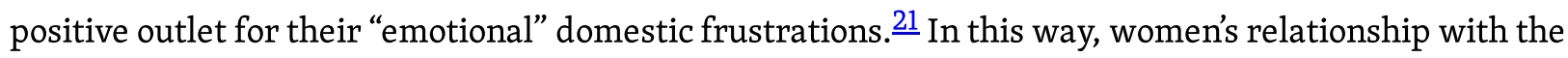
piano was closely tied to the functioning of patriarchal power relations.

Pandering to this middle class female market, piano manufacturers produced smaller pianos which matched domestic interiors of the day and could double as storage cabinets, desks and tables. $\frac{22}{}$ Likewise, sewing machine manufacturers distanced themselves from the aesthetics of the factory with designs that easily assimilated into a domestic setting, in an effort which was likely intended to attract female consumers to their product. $\frac{23}{3}$ Hence, sewing machines were decorated to resemble domestic furnishings, concealed within wooden cabinets or placed on embellished cast-iron bases.

Due to their intended domestic context, sewing machines and pianos became "habitually thought of together" as different varieties of household goods. $\underline{24}$ They were commonly sold in the same salerooms and by the same salespeople, appeared together in trade news publications such as the Musical and Sewing Machine Gazette (first published in 1880) and were sometimes manufactured by the same companies. $\underline{25}$ In the 1860 s, the American company Wheeler \& Wilson manufactured a combination sewing machine and melodeon which assumed the appearance of a domestic sideboard. $\underline{26}$ This device had two foot pedals; one to operate the sewing machine and the other for the organ. 


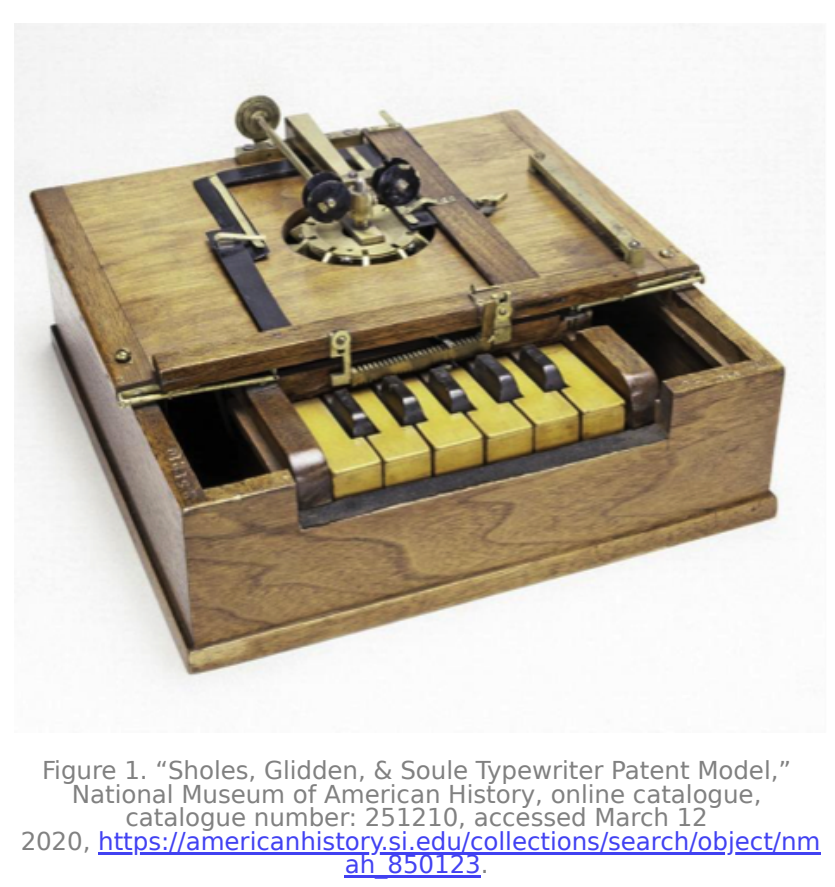

The early design-history of the typewriter indicates that its association with the feminine was constructed from the outset, through design continuities with devices which were already typically used by women - the sewing machine and piano. Piano keys were a feature of many early typewriter designs, including The Sholes, Gidden and Soule Machine, patented in 1868 (see Figure 1). Remington's manufacture of their first models of the sewing machine sat atop a cast-iron decorated base and included a foot pedal which was used to trigger the carriage return. $\underline{27}$ Thus, not only the appearance but also the mechanisms and functioning of these machines were determined by the gender of their intended user. This, in turn, had an impact upon the roles women would perform with machines in the workforce. For example, Helga Nowotny argues that this technological association between typewriter, sewing machine and piano "lent credibility to the idea that 'shorthand typing' seems to have been created for young women or that the typewriter was a feminine tool." $\underline{28}$ Arguably, this may have made it easier to fill office secretary and typist positions with lower-paid female employees.

Public opinion surrounding women's use of the machines in the nineteenth century was rife with contradiction. Sewing machines, for example, were hailed by some as a liberator from domestic drudgery. $\underline{29}$ Involving skills which were transferable to work with other mechanical devices in industrial contexts, they were seen by some to have the power to mould women into more technologically-oriented beings. .30 Annabel Friedrichs argues that "the commonly maleconnotated machine-ness of the sewing machine provided women with an entrance to...the discourse of modernity" and undercut ideologies related to the separate gendered spheres of the home and work. $\underline{31}$ This was met with some strong opposition at the time, some of which was veiled behind moral 
panic about women's sexuality and concerns for their health and safety in industrial clothing manufacturing facilities. $\frac{32}{}$

Karen Offen notes that in nineteenth-century France, the prominence of sweated labour in the clothing industry led to occupational health problems for the female workers. These were attributed by some male doctors at the time to the fact that women were operating industrial machines. $\frac{33}{3}$ Remarkably, a Parisian doctor named Eugène Guibout in his article 'De l'influence des machines à coudre sur la santé et la moralité des ouvritrès' claimed in 1866 that the bi-pedal industrial sewing machines of the time caused the operator's thighs to rub together in such a way that the motion produced "genital excitement." $\underline{4}$ He argued this masturbatory effect was harmful to women's health and that symptoms such as weakness, fatigue, weight-loss and leucorrhea (vaginal discharge) illustrated "the ravages produced by an involuntary masturbation resulting from the play of the machine." 35 His claims were taken seriously by other doctors and were introduced into official debates, such as at the 1866 congress of the First International Workingmen's Association. $\frac{36}{}$ Offen notes that the main participants in this debate were male doctors and workers, with the important exception of Mlle Caroline Garcin. .37 In an attempt to put the debate to rest, Garcin worked with a skilled clockmaker to develop an industrial sewing machine with only one pedal - the standard we continue to use today. Garcin's story demonstrates that the sewing machine has, on multiple counts, had gendered relations designed-in, due to political, gender-biased pressures. As Skåeby and Rahm state, "Machines are never neutral. They are always already entangled in gendered, radicalized and sexualised regimes of truth, saturated with (asymmetrical) power relations." $\underline{38}$

The phenomenon of certain devices being operated by women because of their similarities to previous machines of feminised labour continued into the twentieth century. Vocal simulators and synthesisers developed in the late 1930s and 1940s, including the Voder and Sonovox are examples of this trend. Gender, as Jacob Smith attests, was a "determining factor of the cultural life of voice technologies of the 1940s." 39 The Voder was the first electronic vocal synthesiser, developed by the Bell Telephone Laboratory and demonstrated in New York at the 1939 World Fair by operator Helen Harper. Harper was one of few experts selected from over three hundred all-female applicants and trained over a year to operate this very complex instrument. $\underline{40}$ The Voder had two excitation functions for voiced and unvoiced sounds: a sawtooth oscillator and a random noise generator, respectively. A wrist-bar was used to engage an excitation function, and a foot pedal controlled the pitch of the oscillator. The keys on the keyboard applied various bandpass filters to the sound. Special keys were used to produce plosives (such as $\mathrm{d}$ or $\mathrm{p}$ ) and affricate sounds (such as $\mathrm{j}$ in jog or ch in change). $\underline{\underline{41}}$ 


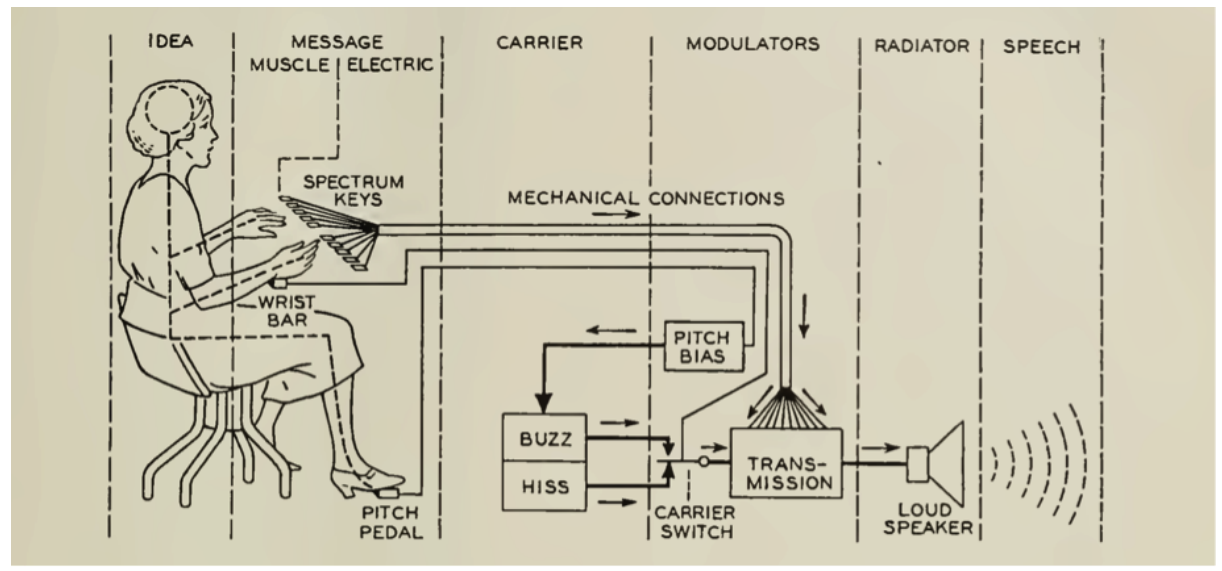

Figure 2. "Schematic Circuit of the Voder," in The Bell System Technical Journal, 19, 1922, 509. Short Hills, N.J: American Telephone and Telegraph Co.

Because of the expert skill required to operate the Voder, the opportunity was reserved for telephone switchboard operators (a traditionally feminine occupation), who had experience working with electronic circuits. $\underline{42}$ However, the operation of the Voder was also closely aligned with that of the piano and hence, as we have seen, the sewing machine and typewriter. The Voder's keyboard appeared "somewhat similar to an old-fashioned parlour organ." $\underline{43}$ It contained ten white keys for vowel sounds and three black keys for consonants. The operator was required to operate multiple keys and pedals at once to create the impression of speech, like the player of an organ. $\underline{44}$

The Voder was not the only vocal simulator of the late 1930s to be almost exclusively operated by women. In the same year in which the Voder was demonstrated at the World Fair in New York, Gilbert H. Wright filed a patent for the Sonovox. This mechanism reproduced a recorded sound via two transducer speakers, which were held directly onto the throat of the operator. The frequencies of the recording vibrated the operator's vocal cords and were then filtered through the changing shape of their throat, tongue and mouth as they mouthed words as if in speech. $\underline{45}$ Non-vocal sounds such as a train whistle could thus be made to 'speak. $\underline{46}$

That a device like the Sonovox was so commonly operated by women has differing explanations to the Voder. Smith identifies that the Sonovox was used commercially in radio advertising to create jingles, and in films to voice the inner thoughts and desires of female characters. $\underline{47}$ Hence, he argues, actresses were hired to speak to what was presumed to be a majority female audience. $\underline{48}$ Advertisements and demonstrations of the Sonovox from the 1940s also evidence that the women who operated the Sonovox were sexually objectified in this role, and that a 'sex sells' mentality drove a trend which saw catchy jingles delivered from the bodies and mouths of traditionally pretty women. For example, a series of Sonovox newspaper advertisements from the mid 1940s depict cartoon drawings of nude women, each holding an advertising placard to partially conceal herself (see 
Figure 3). Here, the placard stands in for the Sonovox as a thin and suggestive layer of mediation between the woman's consumable body and the eyes or ears of the potential buyer of the product she sells.

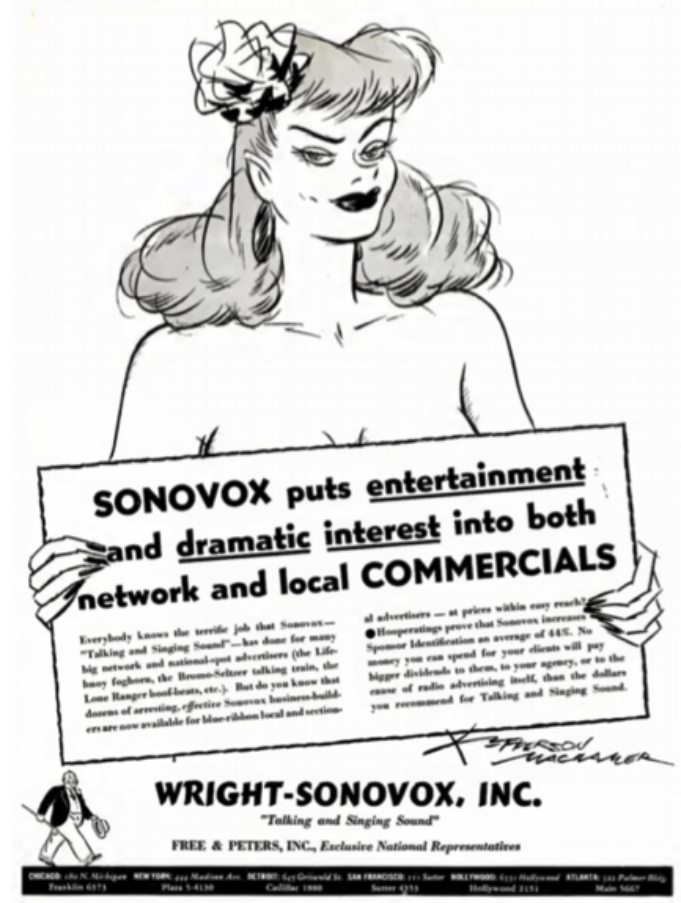

Figure 3. Advertisement for the Sonovox, in Broadcasting and Broadcast Advertising 1945 Yearbook: The Weekly Newsmagazine of Radio Broadcast Advertising, Broadcasting Publications Inc. vol 28 No. 11 -YB, 1945, accessed March 15, 2020, 18. https://www.americanradiohistory.com/Archive-BC-

$\underline{Y B / 1945 / 1945-B C-Y B . p d f}$

In an article from 1946 discussing the use of the Sonovox in commercial radio, a photo shows Janet Eberhart using the Sonovox to voice a radio jingle (see Figure 4). The writer describes Eberhart as a "pretty girl...with lips puckered invitingly," but characterises the sound produced by the Sonovox as a "frightening," "spooky" and "ghostly guttural noise." $\underline{49}$ Eberhart is thus negatively cast as "a symbol... of radio's cultural level." $\underline{50}$ The tone of the article reveals discomfort with the combination of this "pretty girl['s]" body with the harsh sound of a fog horn. $\frac{51}{5}$ Such disparagement conforms with common discourse of the day, in which commercial radio and mass culture more generally were frowned upon by some cultural critics for pandering to what was deemed to be an unsophisticated, predominantly female mass audience. $\underline{52}$ 


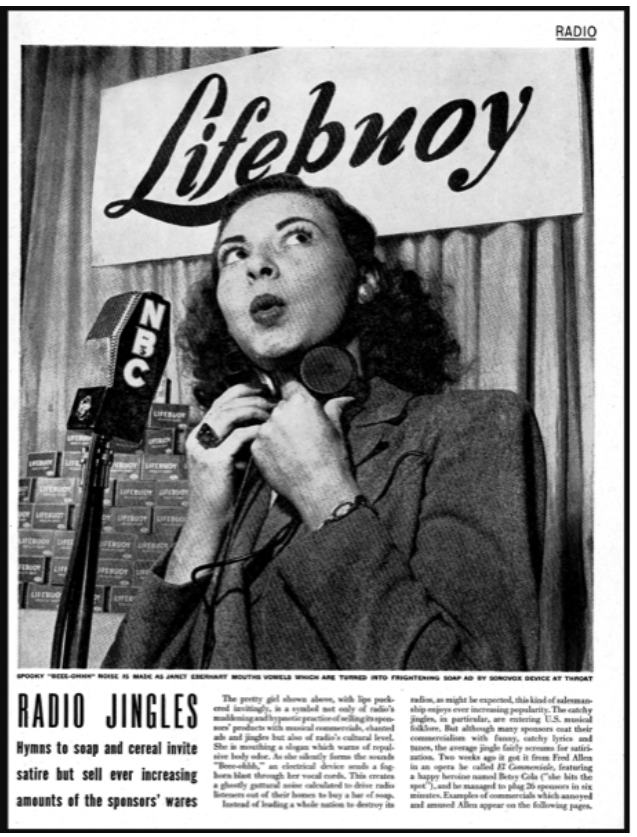

Figure 4. "Spooky "beee-ohhh" noise is made as Janet Eberhard mouths vowels which are tuned throat." Image from "Radio Jingles: Hymns to soap and cereal invite satire but sell ever increasing amounts of the sponsors' wares"'" Life Magazine, 21 no. 25, December 16, 1946, 121.
Earlier devices for vocal simulation - Joseph Faber's 'Euphonia' and Edison's talking dolls - provide other possible clues to this trend of women's prominence in early vocal simulation. Namely, these examples involve white male inventors using the bodies or effigies of women and people of colour like ventriloquists' dummies in the production of simulated vocal sound. For example, Joseph Faber's early talking machine of the midnineteenth century was known as 'Euphonia.' The device involved a bellows which blew air (mimicking the lungs) through a mechanical apparatus which replicated the human throat and vocal organs. These were controlled via a piano-like keyboard. The machine was connected to a humanoid mask, dressed either as a woman or a "Turk." $\underline{33}$ Placing such masks onto non-human machines affirmed the 'otherness' of women and people of colour in relation to the white male inventor, and in the context of the machine's operation, placed them under the control of

the operator. This was a common convention for eighteenth- and early nineteenth-century automatons. As Dustin Adnet states, these machines were often built to mimic "people left out of the emerging political structure, especially women, children and especially, nonwhites." $\underline{54}$ Wolfgang von Kempelen's “Chess-playing Turk" and Jacquet-Droz's (female) organist of the 1770s were other earlier examples of such racialised and gendered machines, whose subjects were reduced to "easily controllable bodies." $\underline{55}$

Thomas Edison's phonographic female dolls, manufactured and sold from 1888 to 1891, provide another example of 'female' automatons being used to produce mechanically reproduced vocal sound. Each of these large and heavy dolls contained a miniature Edison phonograph in her tin chest, which was wound with an external crank to play a twenty second wax recording of a nursery rhyme. Each of these songs was individually recorded for each doll by up to eighteen young women who were hired specifically for this purpose, working in factory cubicles. $\underline{56}$

Commentators who visited Edison's factory noted the uncanny, "startling," "nearly human" effect of voices, similar to those which came "from a ventriloquist's dummy." 57 Paul Flaig argues that it was in fact the female workers who were "reduced to ventriloquised dolls" in the production process, as a promotional myth about the doll's voices being produced by children obscured their repetitive and challenging labour, making them anonymous and invisible. $\frac{58}{}$ This ventriloquism, he argues, offered a 
"controllable version of the Other" to its male creators. $\frac{59}{}$ After the financial failure of his venture, Edison himself reportedly began referring to the dolls as his "little monsters." 60

The gendering of synthesised voices continues to be a pertinent topic in the twenty-first century. As artificially intelligent assistants such as Apple's Siri and Amazon's Alexa integrate into our lives, the corporations developing these tools enforce social norms by gendering the bots artificially using higherpitched voices, traditionally female names, and as commentators have noted, "an often submissive or even flirtatious style." 61 These digital assistants are designed to be obedient and helpful even in the face of verbal sexual harassment and abuse, reinforcing gender stereotypes. $\frac{62}{6}$ Here, we see a historical parallel between contemporary service bots and the women who worked as switchboard operators. Their telephonic voices were selected to embody the supposedly feminine qualities of helpfulness and patience, and were considered to be "much more likely to give the soft answer that turneth away wrath." $\underline{63}$ That contemporary computer engineering teams are staffed by a majority of men also reveals a kind of ventriloquism, whereby male programmers control the way in which 'female' machines interact with human society.

Throughout this paper so far we have seen how gender relations and stereotypes have become an inherent part of technological design, or as Lohan and Faulkner state, how "gender presumptions [are] designed into artefacts." (emphasis mine). $\frac{64}{}$ In the next section, I will investigate "how those same artefacts may be flexibly reinterpreted by users to have different meanings and uses." 65 Donna Harraway states that "technologies and scientific discourses can be partially understood as formalisations, i.e., as frozen moments, of the fluid social interactions constituting them, but they should also be viewed as instruments for enforcing meanings." 66 As an artist, I wish to investigate how these meanings can be re-sampled and re-assembled, to challenge and re-purpose their legacy in a contemporary context.

\section{Studio research}

The studio-based component of this research involved selecting a range of technical artefacts, which were described in the previous section, for use in a performance context. Over several months in the studio, I developed an interconnected interface comprised of different technical artefacts and their components (namely, a sewing machine, talk box, and series of foot pedals). The interface allowed these elements to be modulated and controlled by each other, and by different parts of my body. By combining aspects of these technologies with my body on stage, my intention is to create a dynamic 
woman-machine interface, engaged in a performance which resonates with concepts of femininity, voice, noise, body, nature, technology and technical expertise.

When using the sewing machine in the studio, I approached this device as a sonic artist, untrained in machine sewing. I therefore explored ways of using the machine and its pedal first and foremost as sonic instruments. The removal of the machine from its intended purpose allowed me to ask different questions of this medium, opening up the possible answers it could provide. Namely, I moved from asking the question "how was it used?" to asking "what can it do?" 67 I intentionally allowed intuition and play to drive the initial stages of my research to counter macho audio-tech cultures, which place paramount importance on procedural knowledge of technical equipment. $\underline{68}$

During the initial stages, I discovered other artists who have used the sewing machine in musical contexts, including Stephanie Müller and Lisa Simpson, also known as Agente Costura. This Berlinbased duo make experimental music using hand-made instruments, archival recordings, voice and a range of everyday objects, including amplified sewing machines and other tools of the textile trade, such as scissors, threads and fabrics. In these performances, sewing machines are amplified in the act of sewing to re-contextualise their mechanical sounds in a musical concert setting and re-value the associated women's labour through its placement on a public stage. Although re-contextualized, the machines in Agente Costura's performances remain very much connected to the act of sewing.

In contrast to Simpson and Müller's approach, my aim was to shift focus away from the machine's intended use in order to break with preconceived meanings. The sewing machine is not used to sew in my performance: rather, I have chosen to sonify aspects of the machine's functioning and materiality which we do not perceive with the naked ear. The electromagnetic radiation coming from the machine's motor is transposed to audible range via an electromagnetic microphone. This microphone gives us access to aspects of the material world (the flow of electricity) to which the machine is normally privy, while we are not. Hence, the microphone conceivably allows the machine to 'speak' to us in its own language. This enables us to see or hear beyond the machine's function or use, as the material reality or "implicit knowledge" of the machine is revealed. $\underline{69}$

With this electromagnetic microphone connected, the foot pedal (which is normally used to control the sewing speed), can simultaneously control the volume and tone colour of the electronic noise reproduced via the microphone. To enhance and broaden the sonic possibilities of this interface, I wired three sewing machine pedals from different machines in series, in order to manipulate the flow of electricity on several fronts. This intervention into the electronic functioning of the machine is a kind of 'circuit bending', a method commonly used in media archaeological art practices. $\underline{70}$ Circuit bending involves the modification of the circuitry in consumer electronics to open up new creative possibilities, and to question the "taken-for-granted function of the technology." $\underline{1}$ The use of multiple 
foot pedals in a sonic performance also alludes to popular music contexts since the mid twentieth century, in which the use of numerous effects pedals has been a prevalent characteristic. In my performance, two of the foot pedals are controlled by the feet and one is attached to an instrument harness on my chest. The many cables connecting the different pieces of audio equipment are draped across the sewing machine's wooden cabinet. One cable connects to a pedal strapped directly to my chest, while other parts of the apparatus lead into my mouth. Like arteries or umbilical cords, these lines connect my body into the machine. In this way, I make my body a functioning part of the apparatus. Through this action, I put Harraway's concept of the cyborg into practice, challenging preconceived notions about women's supposed closeness to nature by connecting directly with technology. Moreover, I call on the traditions of feminist performance art which "attempt to disrupt the cultural associations with the female body." $\underline{72}$

Historical apparatuses such as the Sonovox provide an ideal precursor to this kind of practice, where the human body acts as a "sounding board for mechanical sound."프 Using Gilbert Wright's (1942) patent, I familiarised myself with the technical functioning of the Sonovox and constructed my own. I also investigated other similar technologies which allow for mechanical or electronic sound to be modulated by the oral and vocal organs. It was in this process that I came across the talk box - an effects pedal, similar in functioning to the Sonovox in that it uses the operator's mouth as a resonator and allows sound to be filtered via the shape of the mouth. Rather than manually vibrating the operator's vocal cords, the talk box propels sound waves from a loudspeaker through surgical tubing to

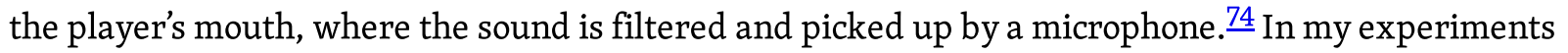
with the self-made Sonovox, I explored playing recorded sounds through the transducer speakers, mouthing words and adding the sounds of breath into the microphone. However, this method was best suited to pre-recorded sounds, as the volume of the modified sounds could not be heard over that of the acoustic sounds of the sewing machine in a live context. This informed my decision to use the talk box instead, as it produced a louder output which could compete with the volume of the other sounds of the performance (see Video 2). 


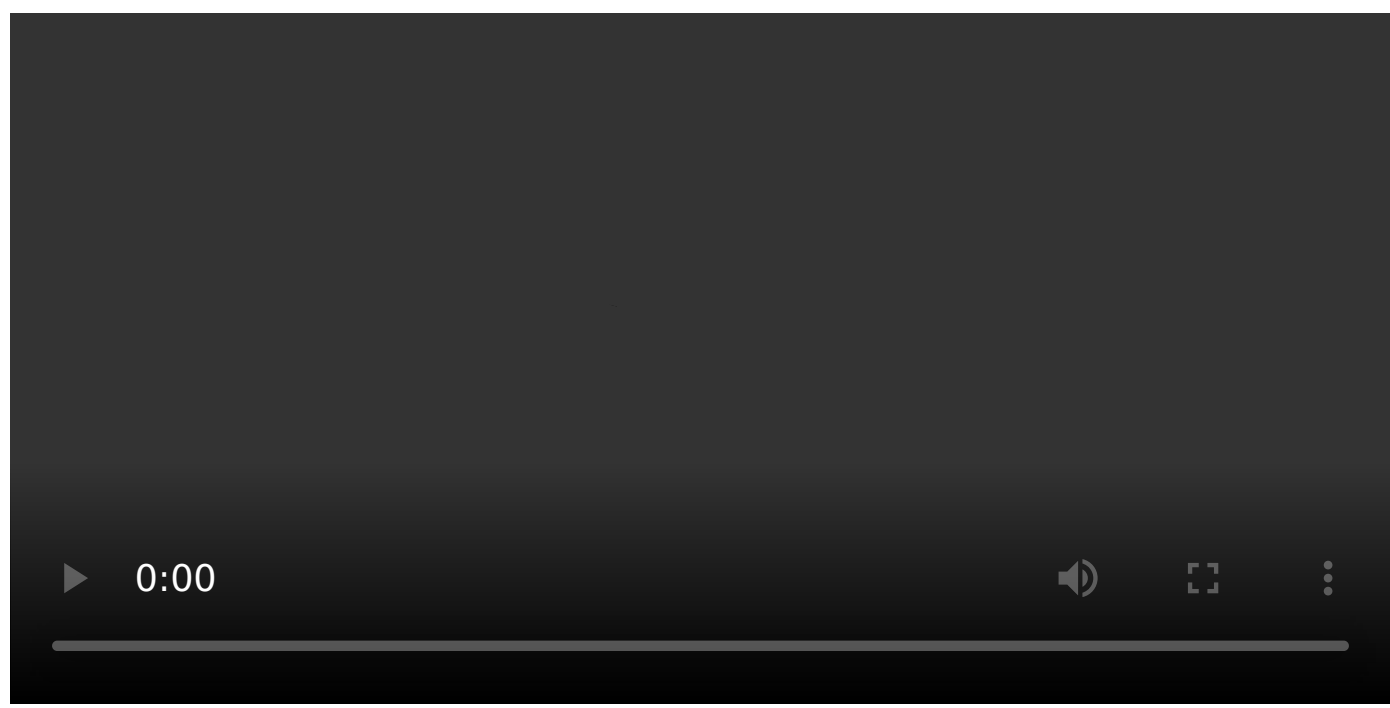

Video 2. Early experiments with the Sonovox [00:00 - 00:46] and talk box [00:46 - 01:30]

The significance of the mouth in this interaction also carries a pertinent gendered association. Anne Carson notes that in ancient Greek and Roman thought, it was commonly held that women have two mouths. $\frac{75}{7}$ This concept is evidenced in the Greek and Latin formation of the words of vagina and mouth, where the word-stem stoma in Greek and os in Latin are prefixed with ano and kato to distinguish between the oral and reproductive organs. $\underline{76}$ Under patriarchal culture to the present day, Carson argues, "both mouths provide access to a hollow cavity which is guarded by lips that are best

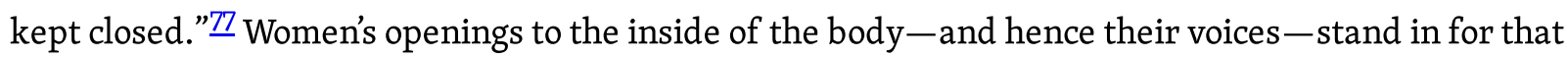
which should be censored: the monstrous and the disorderly.

Such anxieties and associations surrounding women's bodies have been probed and negotiated by performance artists and vocalists such as Juliana Snapper and Laurie Anderson, though a practice of adding foreign objects and technologies to their mouths and vocal apparatus. In Snapper's case, as elucidated by Nina Sun Eidsheim, this practice includes inhibiting her classically trained, operatic voice through singing while suspended upside down or underwater. $\underline{78}$ During Snapper's performance of The Judas Cradle, while suspended in this manner, the audience views a live camera feed showing the fleshy cavity of the inside of Snapper's inverted mouth, an act which resonates with Carson's concept of the 'two mouths'. Snapper likens the act of inhibiting the voice in such a way to the practice of instrument preparation, where foreign objects are added, to a piano or guitar, for example, to distort the instrument's capabilities and thereby create new sounds. $\frac{79}{}$ Eidsheim argues that this 'preparation' may be imagined as "a way to remark on, negotiate, and play with the boundaries between nature and culture: between the female voice historically understood as uncontrollable or natural and the operatic voice as refined and controlled" and evidences a "desire to interrupt and disturb human relationships with instruments and their histories." $\underline{80}$ The talk box performs a similar role in my performance, as a tool which challenges expectations of the kind of voice which might 
emerge from my body. It thereby confronts the contradictory associations of monstrousness and purity projected onto women's bodies more generally.

Feminist performance artist and musician, Laurie Anderson, also 'prepares' her vocal apparatus in her piece Small Voice. In this piece, she places a small speaker inside her mouth and moves her lips to filter the frequencies, modulating the tone colour and volume of the sound emanating from it. In other works, (for example in The Nova Convention) Anderson disrupts preconceptions around gender, body and voice using a harmoniser to lower the pitch of her voice. She sees this practice as an "audio mask," a kind of vocal "drag." 11 This technological transformation of Anderson's voice allows her to play with constructed gender binaries, creating disjunction and slippage between the body she possesses and the one which may be conjured in the mind of the listener. $\underline{82}$

While Anderson specifically focuses on lowering her pitch to appropriate the paradigmatically masculine voice of authority and control, my use of vocal modulation is concerned with the interrelationship between machine sound, gendered body and voice. $\underline{83}$ Like Anderson, I make myself my “own ventriloquist's dummy," controlling the mechanism which speaks through me, and hence

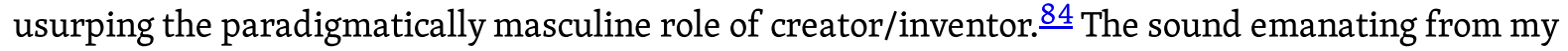
mouth is not pitched to form melody, but remains electronic noise. In emitting this harshness from my body, I lean into cultural tropes which dismiss women's voices and speech as noise, their discussions "meaningless chatter," or raising pitch "hysterical." $\underline{85}$ In this way, women's voices may be "heard as sign of women's essential lack - both of presence and truth." 86 I wrestle with the association of the feminine voice with noise by replacing my voice with that of the machine and weaponising its destructive, non-tranquil sound against the paradigm of male rationality. As Harraway espouses, I "seize the tools" which were used to mark women as "other," and use them instead "to mark the world" around me. $\underline{87}$

By changing the shape of my mouth as it encases the tube of the talk-box's tube, I am able to shift overtones of the machine noise through the harmonic series. Using a 'freeze' pedal I can hold one of these tones and harmonise with it in real time (see 00:01:33 - 00:01:45 in Video 1). Later in the performance, I bring this sound into the semantic realm, mouthing words to make the machine 'speak' to the audience through me (See 00:05:06 - 00:05:45 in Video 1). The use of the talk box in this manner alludes to the common usages of both the Sonovox and Voder in the late 1930s and 1940s. In early experiments, I considered mouthing the words 'she saw me' which Harper produced on the Voder during its demonstration at the World Fair in New York in 1939. .88 I also experimented with mouthing the words 'I see her' in response to the Voder's phrase, as a further acknowledgement of Harper's labour. For this purpose, I made a sound collage of the recorded words from the Voder and recorded this collage onto magnetic tape. Following this, I sent the signal from the tape machine to the talk box, which propelled the sounds into my mouth (see Video 3). 


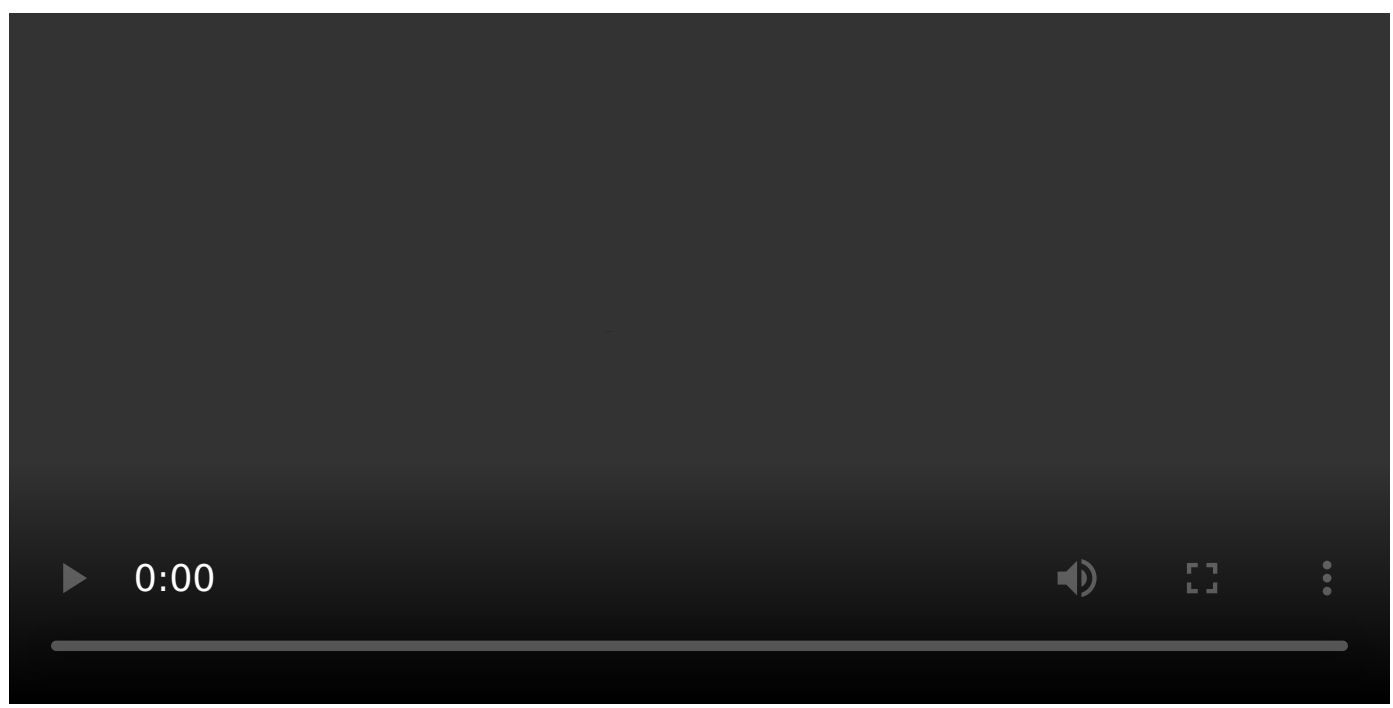

Video 3. Experimenting with interaction between tape machine and talk box - sending recorded words to the talk box and into my mouth.

However, I reasoned that the full impact of these words required prior knowledge of the Voder and its demonstration. For this reason, the performance shifted into closer association with the Sonovox instead. I sampled language from 1940s advertising to form a new text to speak with the talk box, thereby alluding to the commercial context in which the Sonovox was commonly used:

Presenting the Veritas Machine: the latest wonder of science and a timeless classic. Pulsing with the womanly virtues of speed and ferocity, produced electrically! What a wonderful new feeling.

What a wonderful new feeling.

What a wonderful new feeling.

This allusion to sleek advertising language clashes with the machine-like quality of the electronic noise used to voice the words. When communicating information about a product to the public, the sounds of the body such as coughs, stammers, sneezes and wheezing are generally omitted. Francis Dyson argues that in such contexts "the body represents noise, that is, an interference with the transmission of 'truth'." 89 Yet, as I utter these words, I begin to insert the tube of the talk box deeper into my mouth and throat, repeating phrases to abstract their meaning. My physical discomfort becomes apparent as the words dissolve into the sound of gagging. Rather than reproducing common representations of cyborgs which circumvent the imperfections of the human body, here technical mechanisms trigger those human bodily imperfections. Hence, both the 'voice of authority' and the ideal of a woman's body free of 'imperfection' are disrupted by the visceral sonic presence of the body. The illusion of mechanical 'voice' coming from within my body heightens the natural power of the natural voice to "betray the body to which it is lent," as Derrida states, thereby "giv[ing] birth...to another body." $\underline{00}$ 
Freya Jarman-Ivens argues that it is precisely the voice's projection or birthing of a new body, which makes "the voice itself a space highly productive of the queer." 11 Here, a broad definition of 'queer' is employed, (expanded from a strict interchangeability with homosexual identities), where queering is seen as strongly related to questioning and enquiry, "as a practice, a process, an act"of "upsetting, making strange, [or] unsettling." $\underline{22}$ The word 'queer', argues Jarman-Ivens, draws attention to "the invention or construction of the very notion of sexuality and its relationship to identity" (emphasis in original). $\underline{93}$ She argues that both the voice and the cyborg occupy a space on the boundary between nature and culture, between the bodily and the semiotic, which make them powerful tools for the disruption and confusion of gendered divisions. $\frac{94}{}$ Jarman-Ivens contests that the queer potential of the voice is at its strongest when technologies - including the internal, physiological technologies of the body, external human-made audio technologies, as well as Foucauldian technologies of power "become audible." $\underline{95}$ Through my performance practice, I strived to make each of these layers of technology heard, in order to birth the "queer figure" of the cyborg and to disrupt the tropes and expectations surrounding gendered identities and the sewing machine. $\underline{96}$

Other ways of using the sewing machine as a sonic instrument were also explored in the studio throughout the research process, many of which were not ultimately incorporated into the performance. One of the explored paths involved adding additional pieces of hardware and musical instruments to the moving parts of the machine, allowing new sounds to be produced in the course of its movement. In these experiments, I was inspired by the mechanical found object sound sculptures of twentieth-century artist Jean Tinguely. Tinguely allowed a situation of "controlled chance" - a product of the apparatus and its sequence of motion - to determine the mix of sounds his kinetic sculptures produced. $\frac{97}{}$ Using a similar approach, I used the automatic motion of the machine to resonate violin strings, strike bells and tap plates of metal. However, my conceptual focus on exploring the link between the sewing machine, it's gendered history and my gendered body caused me to continue exploring alternative paths.

The next exploration involved using the mechanism of the machine to interact with and modulate archival audio recorded onto magnetic tape. Rubber bands could be attached to the needle's mechanism to intermittently stop and start the tape in a situation of 'controlled chance' which called on Tinguely's mechanical interactions. I also explored attaching magnets and sandpaper to the sewing machine's foot and needle to deteriorate the audio. However, due to the slow, durational aspect of this process, I found it to be unsuited to the fast-paced and immediate modulation which was occurring in other aspects of the performance. 


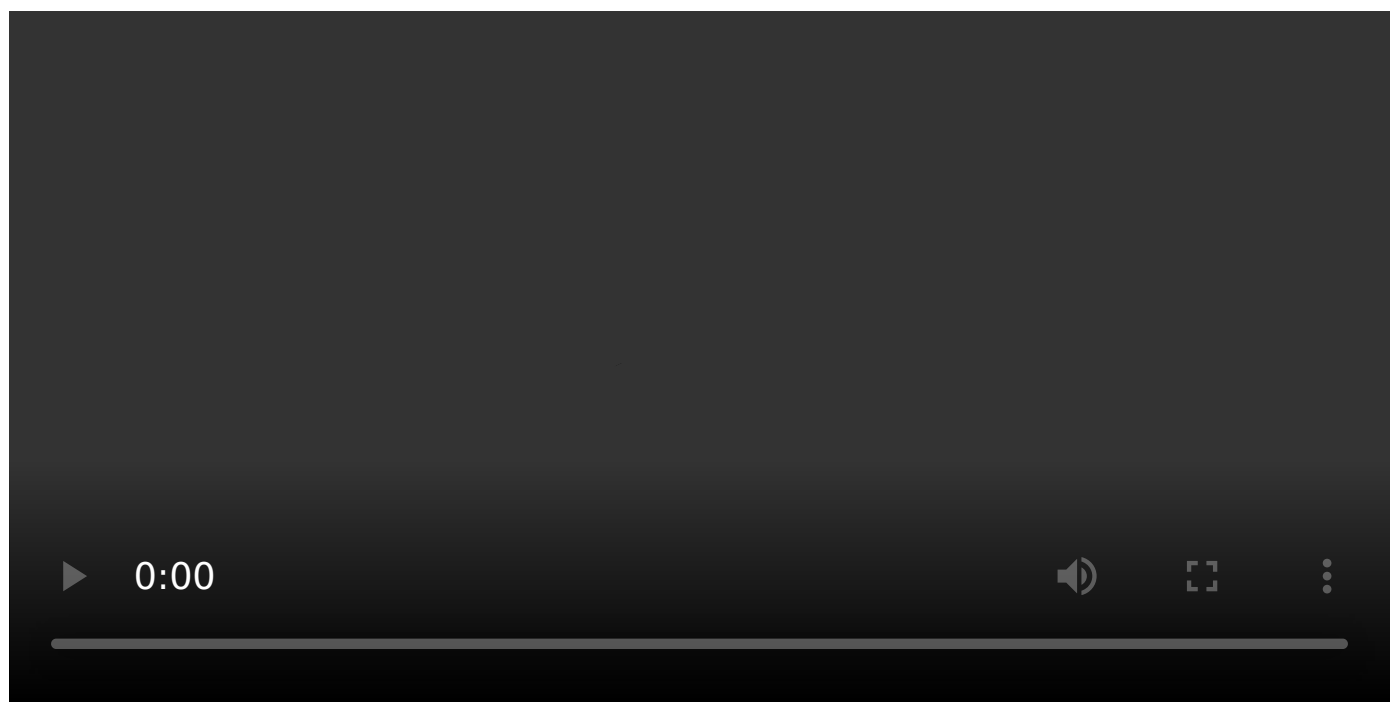

Video 4. Experimenting with felt attached to the sewing machine foot, controlling the playback speed and pitch of a tape loop.

Finally, I explored attaching felt to sewing machine's foot to control the speed and pitch of its playback (see Video 4). Ultimately, this was the method I chose to follow and develop, as it allowed for controlled modulation of the tape loop. This method kept these recordings in my 'expert' hands, rather than resting them purely on the contingent mechanisms of the machine. Moreover, this mechanism provided a chance to include intelligible archival audio in my performance, and thereby incorporate some of the cultural history at the heart of my research more directly and accessibly into the performance.

The archival recordings recorded onto the tape loop were taken from a range of sources: advertisements for sewing machines, demonstration films for the Sonovox and Voder, public service announcements, and educational films about women's heath and employment, including some concerning the use of exercise equipment and safe work practices in factories. These were collated into a sound collage which exposes and satirises the mix of symmetries and contradictions in the discourses surrounding women's bodies and their operation of machines. According to these sources, women require "skilled ability" to operate "the latest wonder[s] of science." 98 However, these machines are also so simple "anyone" could operate them; "all a girl has to do is sit at the controls and hold it back." 99 After all, with new speedy sewing machines on the market, hand sewing is no longer "the most energetic pass-time for a respectable young lady." $\underline{100}$ The audience may infer that the voices in the recordings refer to the very apparatus being operated in the performance, despite the recording quality and intonation of the spoken words revealing their historical origins.

My intervention into these recordings using manual slowing of the tape with the felted foot of the machine, and with a digital delay pedal, also allowed me to intervene in their temporality. The musician and improvisor Pauline Oliveros, who also used a range of analogue and digital delay effects 
throughout her career, claimed she used delay effects as a kind of "time machine." 101 These technologies allowed her to play with herself, as it were, in the past and future, and thereby "expand time." $\underline{102}$ Oliveros' conceptualisation resonates with my desire to intervene in histories in anticipation of an affected future. The sonic artefacts on the tape which mark the sound as 'historical' are blended with digital artefacts from the delay pedal, signalling their contemporary interrogation and quashing nostalgic connotations. Through my intervention, the logic of the historical words recorded on the tape is at times lost. Words repeat themselves and syllables stretch into incomprehensible drones. Under my subversive control, this voice of authority begins to lose its efficacy and command over the transmission of truth.

This tension between tradition and disruption is echoed in the performative and visual elements of the piece. My entrance to the performance space maintains a concentrated air of a classical musicianship and resonates with the demure seriousness of Helen Harper at the 1939 World Fair. My professional black attire and office chair hint at the sewing machine's entwined history with the typewriter. This initial professional demeanour heightens the shock and disjunction felt when the calm is disrupted by the ensuing unbounded noise. A stark dualism of constraint and outburst is maintained sonically and choreographically throughout the performance but shifts back into a state of control as I assume the role of a product demonstrator. With this dualism, I wish to confront the audience with the contradictions of grace and disgrace already existing in society's conceptions of women. To use Eidsheim's words, I negotiate "the dynamic relationship between control and its loss - sonically, corporeally, and socially."

While the contemporary electronic technologies used in the performance are not concealed, other visual elements elude to the different historical contexts from which the work draws its inspiration and meaning. The mid-twentieth-century Veritas sewing machine has been partially deconstructed for the performance, with the metal wheel which was once used to drive the machine manually with the feet, extracted and repurposed. This wheel is set atop a wooden stand on the other side of the performance space (a nod to Duchamp), activating a larger area of the performance environment. In place of the leather driving strap, the magnetic tape containing the audio collage is stretched around the wheel, creating a large loop which is fed through the wooden cabinet and under the foot of the sewing machine, where I control the playback speed for sonic effect. The wheel is lit from below to cast a theatrical shadow, eluding to the mechanical contraptions of the nineteenth century and providing the object with a sense of agency - a larger than life personhood. The relative size of this shadow elevates the role of the machine to that of a second character.

In the final moments of the performance, my own voice is added into the mix of noises produced by the machine. In my studio research into this process, I was interested in creating a sonic amalgam of human and machine noise, through careful and intentional listening to the sounds of the machine. This 
listening process involved an element of risk, as it required placing my ear dangerously close to the violently revolving interior mechanisms. From this position I could vocalise a sound which blends with the shrill screeching and heavy rumbling of the mechanism (See 00:06:07 - 00:06:41 in Video 1). The sound is guttural, visceral and vibrates in the soft palate behind my nose. These bodily sounds resonate with notions of the animalistic and the natural, while the machine conjures the mechanical, and the unnatural. In this way, this moment of the performance challenges and obstructs some of the dualisms at the core of Western, patriarchal thought. As illuminated by Harraway, "the dichotomies between mind and body, animal and human, organism and machine, public and private, nature and culture, men and women, primitive and civilized are all in question ideologically." 104 These are the dualisms which "have all been system to the logics and practices and domination of...all [who are] constituted as others." $\underline{105}$

By linking the machine to myself somatically and technologically, by working intuitively and noisily, by arresting the materials and tools which have marked women as 'other' and by becoming an expert on new methods of their utilisation, I have composed a performance which seizes and re-assembles the gendered cultural associations of apparatuses from the archive of media history.

\section{Conclusion}

When considering the possible goals and methods of a feminist media archaeological practice, Skågeby and Rahm argue "we should open up to exploring specific media technologies ....as a source for plurality and heterodoxy of yet unrealised uses" to ultimately question "what possible futures emerge from this specific technology?" 106 This project has heeded this advice by unpacking the gendered histories of the foot pedal, vocal simulators and sewing machine, and by using these histories as material to speculatively re-forge new meanings and uses for these tools. The talk box, the sewing machine and its foot pedals, as well as archival materials illustrating social attitudes to women's operation of machines, have been used to create a unique interface which interweaves the material and social aspects of gendered media history. Throughout this process, unrealised sonic possibilities and critical interpretations of the archive of media history have been revealed.

It is not only objects of media history which have been repurposed in this process, but also ideas from feminist thinkers of past decades. From a contemporary perspective, concepts like Harraway's cyborg are both radical and antiquated. By placing strong faith in the liberatory potential of new technologies, early cyber-feminist and cyborg discourses supported the notion that new media themselves can bring about social change. Such approaches avoid examining the social contexts which 
are always already bound to technologies, and which determine their designs and the conditions of their use. .107 Media archaeological approaches such as mine challenge the narrative that science and technology inevitably drive the always-upward march of 'progress'. While this project in some ways aims to realise Harraway's ideal, her concept takes on new meanings in this context. My performative appropriation of older technologies identifies the liberatory potential of technologies in their reconception, through re-invention of the ways they can be used and understood. In this way, I avoid "becoming trapped in an over-determined situation" where all of history (including the future) is "always already part of a given known development." 108

Ironically, this project has also been strongly impacted by an unforeseen future. The fact that the live performance had to be indefinitely postponed had a strong influence on how I reflect on the research at this point in time. Through the creation of video-documentation of the performance at its current stage of development, I have been able to put myself in the shoes of the audience, to perceive more clearly the work's strengths and weaknesses.

Upon hearing the recorded audio for the first time, I noticed the lack of acoustic sounds from the machine which I can hear from my position on the stage. As this performance was planned to be shown in a small space for a small audience, I hadn't anticipated that these sounds would need to be amplified. Some of the strength of this performance comes from the shock of unrealised expectations stemming from gender-stereotypes. .109 We see a woman sitting at a sewing machine, we hear screeching, harsh, electronic noise. This clash between the sonic and visual cues is accompanied by the aggressive friction of different kinds of noise - the acoustic noise of the motor (a sound of modernity) and the electromagnetic noise (a sound of post-modernity). Luigi Russolo linked the advent of machinery and the historical moment of the nineteenth- century to the "birth" of noise, his predication being that the further proliferation of technology, and their accompanying noises, would transform the human soundscape. $\frac{110}{}$ Therefore, the different kinds of noise present in my performance are combined, as Russolo espoused, "according to...artistic fantasy," yet still speak to particular moments in history. $\underline{111}$ In order for the audience to experience this sampling and combination of noises which are connected to the past, I introduced the acoustic rumblings, moans and rattling of the sewing machine to the mix of amplified sounds in the live performance.

The rendition of this performance as a video had other significant impacts upon the work. During the planned live performance, the audience would have been free to move around the equipment and the set, to observe the mechanical and electronic interactions more closely. The video performance however, through the selective view of the camera, became more closely focused on my body, face and particularly my interactions with the tube of the talk box. This also had the effect of highlighting my role as an operator of the machine, while de-emphasising the agency of the machine itself. What has emerged incidentally from the limitations is a work which sits between performance documentation 
and video art. In the future, this is an aspect I could also consider exploring further in a second realisation of the concept as video art.

It is not only the experience of watching my video-performance which has alerted me to continued opportunities for further research on this topic. Indeed, from the outset of this project, I aspired to link the nineteenth- and early twentieth-century history of the sewing machine in this Western context to its significance in a contemporary global context. In the late twentieth- and early twentyfirst-centuries, industrial sweatshop labour has been rife in the textile industry, particularly in the Global South, providing for the fast fashion industries of higher income countries. $\frac{112}{\text { The sewing }}$ machine takes on new and critical layers of significance in the context of this globalised, exploitative and persistently gendered labour. I felt conflicted in trying to incorporate these themes into my research, in part because of the widening scope of the study, and also because as a Western woman, I hesitate to tell stories which arguably do not belong to me. Certainly, this aspect of the sewing machine's social construction is of strong relevance and would make for a fascinating research topic.

More broadly, this project provides one new instance or investigation of an artistic method by which women and other disadvantaged groups can intervene in and relate to their histories. That is, not only by making power relations visible, but harnessing and re-appropriating them for their own purposes. De-colonial artists such as Tony Albert have shown that artistic agency can be used to appropriate the signs and symbols of the oppressor, holding up a mirror to the colonial gaze to highlight unquestioned norms. Further methodologies have been suggested by American electronic music composer and scholar Beth Coleman who espouses the consideration of race as a "technology," thereby liberating the concept of race "from an inherited position of abjection toward a greater expression of agency," re-envisaging it as tool which can be freely used. $\underline{113}$ Through this reconceptualisation, Coleman aims to change the "terms of engagement with an all-too-familiar system of representation and power." $\underline{114}$ Like Albert and Coleman, in this project I have reframed perceived weaknesses or disadvantages as tools and methods to challenge accepted systems, representations and understandings. This project refutes the idea that technologies can be socially or culturally 'neutral' and highlights social norms by playing games with the unspoken rules which surround them. Thus, it contributes new knowledge to an artistic and political approach.

While the performance was developed with valuable ongoing feedback from supervisors and peers, the public availability of the video documentation provides further opportunities for understanding how the work can be interpreted and received and this too can feed back into further research and discoveries. Hannula, Suoranta and Vadén note that the public parts of a project of artistic research, such as my performance "are really not separate from the process: they feed back into it, maintaining and nourishing it, questioning and even possibly jeopardizing it." 115 This, they argue "is also the arena where the productive dilemmas of the field to which one is committed can be actualized, where the 
conditions of conditions can be pushed and pulled." $\underline{116}$ While I may have otherwise considered this project complete, I now see this stage as but one step in a process which could be perpetually explored and developed. The postponement of the live performance, which at first appeared to be a hindrance, may in fact be an opportunity to do just that.

\section{Bibliography}

Adnet, Dustin A. The American Robot: A Cultural History. Chicago and London: The University of Chicago Press, 2020.

Armitage, John. "From Discourse Networks to Cultural Mathematics: An Interview with Friedrich A. Kittler." Theory, Culture \& Society 23, no. 7-8 (December 2006): 17-38.

Beetem Acker, Anne. "Talk box." In The Grove Dictionary of Musical Instruments. 2nd Edition. Oxford University Press, 2014, accessed March 15, 2020.

Carson, Anne. "The Gender of Sound." In Audio Culture: Readings in Modern Music, Revised Edition, edited by Christoph Cox and Daniel Warner, 43-59. New York: Bloomsbury Academic, 2017.

Casson, Herbert N. The History of the Telephone. 4th Edition. Chicago: A. C. McClurg \& Co, 1911.

Coleman, Beth. "Race as Technology." Camera Obscura: Feminism, Culture, and Media Studies 24, no. 170 (January 12009 ): 177-207.

Dados, Nour and Raewyn Connell. “The Global South" Contexts 11, no. 1 (winter, 2012): 12-13, American Sociological Association.

Davies, Lawrence E. "Machine that Talks and Sings Has Tryout; Electrical Voder Will Speak At Fair Here." New York Times, January 6, 1939. Accessed February 25, 2020. http://search.proquest.com/docview/102786809/.

Dawson, Victoria. “The Epic Failure of Thomas Edison's Talking Doll." Smithsonian Magazine Online, June 1 2015. Accessed February 25, 2020. https://www.smithsonianmag.com/smithsonianinstitution/epic-failure-thomas-edisons-talking-doll-180955442/.

Derrida, Jacques. “Voice II.” In Points: Interviews 1976-1994, translated by Verena Andermatt Conley. Stanford: Stanford University Press, [1992] 1995. 
Dyson, Frances. “The Genealogy of the Radio Voice." In Radio Rethink: Art Sound and Transmission, edited by Diana Augaitis and Dan Lander. Banff: Walter Phillips Gallery, 1994.

Eckhardt, Julia and Leen De Graeve. The Second Sound: Conversations on Gender and Music. Gent: Umland Editions, 2015.

Eidsheim, Nina Sun. Sensing Sound: Singing \& Listening as Vibrational Practice. Durham: Duke University Press, 2015.

Ellis, John. "Between Human and Machine: The Operating System." Journal of Contemporary Archaeology 2, no. 1 (2015): 24-28.

Ernst, Wolfgang. "Close to the Signal: About Radical Media Archaeology." Conference Media Matter: Media-Archaeological Research and Artistic Practice. University of Stockholm. November 27, 2019.

Ernst, Wolfgang. "Radical Media Archaeology (its epistemology, aesthetics and case studies." In Pau Alsina, Ana Rodríguez and Vanina Y. Hofman (coords.). "Media Archaeology.” Artnodes. No. 21: 35-43, 2018, UOC, doi.10.7238/a.v0i21.3205.

Ernest, Wolfgang. Digital Memory and the Archive (Minneapolis: University of Minnesota Press, 2013). Flaig, Paul. "Yesterday's Hadaly: On Voicing a Feminist Media Archaeology." Camera Obscura 33, no. 98 (January 12018): 105-137.

Foucault, Michel. The Archaeology of Knowledge. London and New York: Routledge, [1969] 2002.

Friedrichs, Annabel, "Sewing Modernity: How the Sewing Machine Allowed for a Distinctively Feminine Experience of Modernity" in Aspeers 11 (2018): 51-

75. http://www.aspeers.com/sites/default/files/pdf/friedrichs.pdf.

Gold, Ben, Nelson Morgan, Dan Ellis. Speech and Signal Processing: Processing and Perception of Speech and Music. 2nd Edition. Hoboken, New Jersey: John Wiley \& Sons, Inc, 2001.

Goldberg, Roselee. Laurie Anderson. London: Thames and Hudson, 2000.

Hannula, Mika, Juha Suoranta, Tere Vadén. Artistic Research Methodology: Narrative, Power and the Public. New York: Peter Lang Publishing Inc, 2014.

Harraway, Donna. "A Cyborg Manifesto: Science, Technology and Socialist-Feminism in the Late 20th Century." In The International Handbook of Virtual Learning Environments, edited by Joel Weiss, Jason Nolan, Jeremy Hunsinger, and Peter Trifonas, 117-158. Dordrecht: Springer Netherlands, [1985] 2006. 
Hertz, Garnet and Jussi Parikka. “Zombie Media: Circuit Bending Media Archaeology into an Art Method." Leonardo vol 45. no. 5 (2012): 424-430.

Hilmes, Michele. “Desired and Feared: Women's Voices in Radio History." In Television, History, and American Culture: Feminist Critical Essays, edited by Mary Beth Haralovich and Lauren Rabinovitz, 1735. Durham: Duke University Press, 1999.

Hutamo, Erkki. "Art in the Rear-View Mirror: The Media-Archaeological Tradition in Art." in A Companion to Digital Art, First Edition, edited by Christiane Paul, 69-110. Hoboken, NJ: John Wiley \& Sons, 2016.

Huhtamo, Erkki and Jussi Parikka. Media Archaeology: Approaches, Applications, and Implications. Berkeley and Los Angeles: University of California Press, 2011.

Huyssen, Andreas. After the Great Divide: Modernism, Mass Culture, Postmodernism. Bloomington: Indiana University Press, 1986.

Jarman-Ivens, Freya. Queer Voices: Technologies, Vocalities, and the Musical Flaw. New York: Palgrave Macmillan, 2011.

Kramer, Lawrence. "From Clockwork to Pulsation: Music and Artificial Life in the Eighteenth Century." In Experimental Affinities in Music, edited by Paulo de Assis, 147-167. Leuven: Leuven University Press, 2015.

Kittler, Friedrich A. Discourse Networks 1800/1900. Translated by Michael Metteer and Chris Cullens. Stanford: Stanford University Press, [1985] 1990.

Lane, Cathy. "Women as Animal, Women as Alien: Reclaiming Women's Demonic Voices." In Grounds for Possible Music: On Gender, Voice, Language and Identity, edited by Julia Eckhardt, 97-103. Berlin: Errant Bodies Press, 2018.

Life Magazine. "Radio Jingles: Hymns to Soap and Cereal Invite Satire but Sell Ever Increasing Amounts of the Sponsors' Wares." December 16, 1946. 21 no. 25: 121.

Loesser, Arthur. Men, Women and Pianos: A Social History. New York: Dover Publications, 1954.

Lohan, Maria and Wendy Faulkner. "Masculinities and Technologies: Some Introductory Remarks." Men and Masculinities 6, no. 4 (April 2004): 319-329.

Mersch, Dieter. “Epistemologies of Aesthetics.” Translated by Laura Radosh. Zürich Diaphanes, 2015. 
Meurer, Ulrich. "The Shards of Zadar: A (Meta-)Archaeology of Cinema." In Classics and Media Theory, edited by Pantelis Michelakis, 187-210. Oxford: Oxford University Press, 2020.

National Museum of American History: Behring Center. "Sholes, Glidden, \& Soule Typewriter Patent Model." n.d. Accessed March 12, 2020. https://americanhistory.si.edu/collections/search/object/nmah 850123.

New York Press. "Talks With Wise Dolls: Thomas A. Edison, the Great Inventor, Is Their Papa." The Thomas Edison Papers (Online Archive) November 11, 1939. Accessed February

26, 2020. http://edison.rutgers.edu/NamesSearch/SingleDoc.php?DocId=SC88132A\&searchDoc=Enter.

Nielsen, Wendy C. "Romantic Tales of Pseudo-Automata: Jacques de Vaucanson and the Chess-Playing Turk in Literature and Culture." In Romantic Automata: Exhibitions, Figures, Organisms, edited by Michael Demson and Christopher R. Clason. chap. 4 Rutgers University Press. E-book, 2020, accessed June 15, 2020. Retrieved from https://www.scribd.com/read/455818470/Romantic-AutomataExhibitions-Figures-Organisms\#.

Nowotny, Helga. Cultures of Technology and the Quest for Innovation. New York and Oxford: Berghahn Books, 2006.

Offen, Karen. "Powered by the Woman's Foot: a Documentary Introduction to the Sexual Politics of the Sewing Machine in Nineteenth-Century France" Women's Studies Inl. Forum, 2. no. 2 (1988): 93-101.

Parikka, Jussi. What is Media Archaeology? Cambridge: Polity Press, 2012.

Power, Nina. "Woman Machines: the future of Female Noise." In Noise \& Capitalism, edited by Mattin Iles and Anthony Iles, 97-103. Arteleku Audiolab, 2009.

Rahm, Lina and Skågeby, Jörgen. "What is Feminist Media Archaeology?" Communication +1, 7 no. 1: Article 7, 2018.

Reimann, Sandra Beate. Méta-Harmony: Music Machines and Machine Music in Jean Tinguely's Oeuvre. Basel: Museum Tinguely \& Kerber Art, 2016.

Rodgers, Tara. Pink Noises: Women on Electronic Music and Sound. Durham and London: Duke University Press, 2010.

Russolo, Luigi. The Art of Noises: Futurist Manifesto. Translated by Robert Filliou. UbuClassics, [1913] 2004.

Schwartz, Hillel. “Torque: The New Kinaesthetic of the Twentieth Century.” In Incorporations, edited by Jonathan Crary and Sanford Kwinter, 71-127. New York: Urzone, 1992. 
Smith, Jacob. “Tearing Speech to Pieces: Voice Technologies of the 1940s." Music, Sound, and the Moving Image ii, no. 2 (October 2008): 183-206.

Specia, Megan. "Siri and Alexa Reinforce Gender Bias, U.N. Finds." The New York Times, May 22, 2019. Accessed February 22, 2020. https://www.nytimes.com/2019/05/22/world/siri-alexa-ai-genderbias.html.

Striff, Erin. “Bodies of Evidence: Feminist Performance Art.” Critical Survey 9, no. 1 (1997): 1-18.

Thornham, Helen and Angela McFarlane. "Articulating Technology and Imagining the User: Generating Gendered Divides across Media." In Renewing Feminisms: Radical Narratives, Fantasies and Futures in Media Studies, edited by Helen Thornham and Elke Weissmann, 185-198. I. B. Tauris \& Company, Ltd, 2013.

Ulaby, Neda. “Edison's 'Little Monsters' Restored To Their Original Freakishness." Weekend Edition Saturday, NPR News, Radio Transcript, August 1 2015. Accessed February 25, 2020. https://www.npr.org/2015/08/01/428311627/edisons-little-monsters-restored-to-their-originalfreakishness? $\mathrm{t}=1582706035338$.

Vorachek, Laura. "The Instrument of the Century: The Piano as an Icon of Female Sexuality in the Nineteenth Century." George Eliot - George Henry Lewes Studies, no. 38/39 (September 2000): 26-43.

West, Mark, Rebecca Kraut and Han Ei Chew. "I'd Blush if I Could: Closing Gender Divides in Digital Skills through Education." UNESCO and EQUALS Skills Coalition, 2019. Accessed March 12, 2020. https://unesdoc.unesco.org/ark:/48223/pf0000367416.

Wieland Howe, Sondra. Women Music Educators in the United States: A History. Lanham, Md: Scarecrow Press, 2013.

Wosk, Julie. Women and the Machine: Representations from the Spinning Wheel to the Electronic Age. Baltimore: The John Hopkins University Press, 2001.

Wright, Gilbert M. "Means and Method of Producing Sound Effects." United States Patent Office, 2273078, filed March 27 1939, issued February 17, 1942.

\section{Media Cited}


AT\&T Tech Channel. “AT\&T Archives: Operator! (1938) (Bonus Edition).” YouTube video, 21:57. April 12, 2012. Accessed January 12, 2020. https://www.youtube.com/watch?v=nEy7Zb1Noj $\underline{8}$.

British Pathé. "Machine Made Voices! (1939).” YouTube video, 1:05. April 13, 2014. Accessed February 28, 2020. https://www.youtube.com/watch?v=Rld73C5Rfh4.

British Pathé. “Sewing Machines - Old and New (1960)." YouTube video, 2:52. April 13, 2014. Accessed December 20, 2019. https://www.youtube.com/watch?v=paX-gwtSTIM\&t=5s.

Hermes Negrão. “THE RELUCTANT DRAGON by Walt Disney Sonovox." YouTube video, 1:14. February 25, 2009. Accessed December 11, 2019. https://www.youtube.com/watch?v=blhqeWpwwkA.

VintageCG. "VODER (1939) - Early Speech Synthesizer." YouTube video, 0:43. April 4, 2011. Accessed November 20, 2019. https://www.youtube.com/watch?v=0rAyrmm7vv0.

\section{Biography}

Lottie Sebes is a Berlin-based artist and researcher from Sydney, Australia with an artistic practice spanning the disciplines of sculpture, video, sound, installation and performance art. Sebes completed her Bachelor of Fine Arts with Distinction at the University of New South Wales. Thereafter, she received First Class Honours in Visual Arts at the University of Sydney, and was awarded the prestigious University Medal in 2016. She is a current recipient of the Eleanor Sophia Wood Postgraduate Research Travelling Scholarship and is undertaking a Masters in Sound Studies and Sonic Arts at the University of the Arts in Berlin.

www.lottiesebes.com

\section{Footnotes}

1. Hillel Schwartz, "Torque: The New Kinaesthetic of the Twentieth Century," in Incorporations, ed. Jonathan Crary and Sanford Kwinter (New York: Urzone 1992), 71-127.

2. Ibid., 105. 
3. Erkki Huhtamo and Jussi Parikka, Media Archaeology: Approaches, Applications, and Implications (Berkeley and Los Angeles: University of California Press, 2011), 3.

4. Michel Foucault, The Archaeology of Knowledge (London and New York: Routledge, [1969] 2002). 5. Friedrich A. Kittler, Discourse Networks $1800 / 1900$, trans. Michael Metteer and Chris Cullens (Stanford: Stanford University Press, [1985] 1990), 369. $\longleftarrow$

6. Huhtamo and Parikka, Media Archaeology, 28.

7.

Jussi Parikka, What is Media Archaeology? (Cambridge: Polity Press, 2012), 67;

John Armitage "From Discourse Networks to Cultural Mathematics: An Interview with Friedrich A. Kittler," in Theory, Culture \& Society 23, no. 7-8 (December 2006); Huhtamo and Parikka. Media Archaeology, 27-28. $\doteq$

8. Wolfgang Ernst, Digital Memory and the Archive (Minneapolis: University of Minnesota Press, 2013) $49,68 . \subseteq$

9. Ibid., 69. $\subseteq$

10. Lina Rahm and Jörgen Skågeby “What is Feminist Media Archaeology?" Communication +1, 7 no. 1: Article 7 (2018): 2.

11. Donna Harraway, "A Cyborg Manifesto: Science, Technology and Socialist-Feminism in the Late 20th Century," in The International Handbook of Virtual Learning Environments, ed. Joel Weiss, Jason Nolan, Jeremy Hunsinger, and Peter Trifonas (Dordrecht: Springer Netherlands, [1985] 2006). 12. Ibid., 140.

13.

Erkki Hutamo, "Art in the Rear-View Mirror: The Media-Archaeological Tradition in Art," in A Companion to Digital Art, First Edition, ed. Christiane Paul (Hoboken, NJ: John Wiley \& Sons. 2016), 72;

Ernst, "Close to the Signal";

Wolfgang Ernst's writings on 'radical' media archaeology (2018) also describe a distinctly, nonhistorical approach to media archaeology, which emphasises the non-discursive meaning of technical apparatuses - an approach this project does not adopt.

14. Dieter Mersch, Epistemologies of Aesthetics, trans. by Laura Radosh (Zürich: Diaphanes, 2015), 9. 
15. Ibid., 46.

16. Ibid. $\bullet$

17. Ulrich Meurer, “The Shards of Zadar: A (Meta-) Archaeology of Cinema," in Classics and Media Theory, ed. Pantelis Michelakis (Oxford: Oxford University Press, 2020), 205.

18. Ibid. $\triangleq$

19.

AT\&T Tech Channel, “AT\&T Archives: Operator! (1938) (Bonus Edition)," April 12, 2012, accessed January 12, 2020, https://www.youtube.com/watch?v=nEy7Zb1Noj $\underline{\text {; }}$;

Initially work at telephone switchboards was provided by a different source of cheap labour teenage boys. However, this group were deemed to be too impolite and unruly for the job, "immune to all schemes of discipline". So, "in place of the noisy and obstreperous boy came the docile, softvoiced girl." Herbert N. Casson, The History of the Telephone, 4th Edition (Chicago: A. C. McClurg \& Co, 1911), 170.

$\underline{-}$

20. Laura Vorachek, "The Instrument of the Century: The Piano as an Icon of Female Sexuality in the Nineteenth Century," George Eliot - George Henry Lewes Studies, no. 38/39 (September 2000): 26. 21. Ibid., 28. $\doteq$

22. Ibid. $\doteq$

23. Julie Wosk, Women and the Machine: Representations from the Spinning Wheel to the Electronic Age (Baltimore: The John Hopkins University Press, 2001), 31. $ヒ$

24. Arthur Loesser, Men, Women and Pianos: A Social History (New York: Dover Publications, 1954), 561.

25. Ibid. $\doteq$

26. Sondra Wieland Howe, Women music educators in the United States: A History (Lanham, Md: Scarecrow Press, 2013), 51. $\doteq$

27. Helga Nowotny, Cultures of Technology and the Quest for Innovation (New York and Oxford: Berghahn Books, 2006), 77.

28. Ibid. $\triangleq$ 
29. Karen Offen, "Powered by the Woman's Foot: A Documentary Introduction to the Sexual Politics of the Sewing Machine in Nineteenth-Century France," Women's Studies Inl. Forum 2. no. 2. (1988): 93. $\leftrightarrows$

30. Wosk, Women and the Machine, 28. $\doteq$

31. Annabel Friedrichs, "Sewing Modernity: How the Sewing Machine Allowed for a Distinctively Feminine Experience of Modernity," Aspeers 11 (2018): $54 . \boxminus$

32. Offen, "Powered by the Woman's Foot," $94 . \pm$

33. Ibid., 28. $\subseteq$

34. Ibid., $96 . \doteq$

35. Ibid., 97. $\subseteq$

36. Ibid., $94 . \boxminus$

37. Ibid. $\doteq$

38. Rahm and Skågeby, "What is Feminist Media Archaeology?" $5 . \leftrightharpoons$

39. Jacob Smith, "Tearing Speech to Pieces: Voice Technologies of the 1940s," Music, Sound, and the Moving Image ii, no. 2 (October 1, 2008): 183.

40. Ibid., 193.

41. Ben Gold, Nelson Morgan and Dan Ellis, Speech and Signal Processing: Processing and Perception go Speech and Music, 2nd Edition (Hobeken, New Jersey: John Wiley \& Sons, Inc. 2001), $10 . \boxminus$

42. Smith, "Tearing Speech to Pieces," 193.

43. Lawrence E. Davies, "Machine that Talks and Sings Has Tryout; Electrical Voder Will Speak At Fair Here," The New York Times (January 6, 1939), $1 . \subseteq$

44. Smith, “Tearing Speech to Pieces," 203.

45. Gilbert M. Wright, "Means and method of producing sound effects," United States Patent Office, 2273078, filed March 27, 1939, issued February 17, 1942. $\boxminus$

46. British Pathé, “Machine Made Voices! (1939)," April 13, 2014, accessed February 28, 2020, https://www.youtube.com/watch?v=Rld73C5Rfh4. 
47. Smith, "Tearing Speech to Pieces," 183.

48. Ibid., 192-197.

49. "Radio Jingles: Hymns to Soap and Cereal Invite Satire but Sell Ever Increasing Amounts of the Sponsors' Wares," Life Magazine, 21 no. 25 (December 16, 1946), 121.

50. Ibid. $\doteq$

51. Ibid. $\subseteq$

52.

Andreas Huyssen, After the Great Divide: Modernism, Mass Culture, Postmodernism (Bloomington: Indiana University Press, 1986), 47;

Michele Hilmes, “Desired and Feared: Women's Voices in Radio History," in Television, History, and American Culture: Feminist Critical Essays, ed. Mary Beth Haralovich and Lauren Rabinovitz (Durham: Duke University Press, 1999), 29.

53. Ibid., 186.

54. Dustin A. Adnet, The American Robot: A Cultural History (Chicago and London: The University of Chicago Press, 2020), 32. $\subseteq$

55.

Lawrence Kramer, "From Clockwork to Pulsation: Music and Artificial Life in the Eighteenth Century" in Experimental Affinities in Music, ed. Paulo de Assis (Leuven: Leuven University Press, 2015), 157-158;

Wendy C. Nielsen, "Romantic Tales of Pseudo-Automata: Jacques de Vaucanson and the ChessPlaying Turk in Literature and Culture," in Romantic Automata: Exhibitions, Figures, Organisms, ed. Michael Demson and Christopher R. Clason (Rutgers University Press, 2020), chap. 4, accessed 15 June 2020, https://www.scribd.com/read/455818470/Romantic-Automata-Exhibitions-FiguresOrganisms\#; Adnet, The American Robot, 33.

56.

Victoria Dawson, “The Epic Failure of Thomas Edison's Talking Doll," Smithsonian Magazine Online, June 1, 2015, accessed Februrary 25, 2020, https://www.smithsonianmag.com/smithsonianinstitution/epic-failure-thomas-edisons-talking-doll-180955442/;

Paul Flaig, "Yesterday's Hadaly: On Voicing a Feminist Media Archaeology," Camera Obscura, Durham 33, no. 98 (January 1, 2018): 119. 
57. "Talks With Wise Dolls: Thomas A. Edison, the Great Inventor, Is Their Papa," The Thomas Edison Papers (1888) (online Archive, November 11, 1939),

http://edison.rutgers.edu/NamesSearch/SingleDoc.php?.DocId=SC88132A\&searchDoc=Enter.. 58. Paul Flaig, "Yesterday's Hadaly: On Voicing a Feminist Media Archaeology." Camera Obscura 33, no. 98 (January 12018), 122.

59. Ibid., 125. $\subseteq$

60. Neda Ulaby, “Edison's 'Little Monsters' Restored To Their Original Freakishness,” Weekend Edition Saturday, NPR News, Radio Transcript, published August 1, 2015, accessed 25 February, 2020, https://www.npr.org/2015/08/01/428311627/edisons-little-monsters-restored-to-theiroriginal-freakishness?t=1582706035338. $\doteq$

61. Megan Specia, "Siri and Alexa Reinforce Gender Bias, U.N. Finds," The New York Times (May 22, 2019), accessed 22 February, 2020, https://www.nytimes.com/2019/05/22/world/siri-alexa-aigender-bias.html.

62. Mark West, Rebecca Kraut and Han Ei Chew, "I'd Blush if I Could: Closing Gender Divides in Digital Skills through Education," UNESCO and EQUALS Skills Coalition, published 2019, accessed March 12, 2020, 106, https://unesdoc.unesco.org/ark:/48223/pf0000367416.

63.

AT\&T Tech Channel, "AT\&T Archives";

Casson, The History of the Telephone, 172. $\boxminus$

64. Maria Lohan and Wendy Faulkner, "Masculinities and Technologies: Some Introductory Remarks," Men and Masculinities, 6, no. 4, (April 2004): 322.

65. Ibid. $\subseteq$

66. Harraway, “A Cyborg Manifesto," 130. 67. 
John Ellis elaborates on the divergent media archaeological perspectives which are born from asking these different questions of an unfamiliar machine. The question ("how was It used?") prompts an engagement with the "human/machine interface as a social process," he argues. This involves investigating the machine's users, contexts and the "processes of which it was a part". In contrast, the question "what can it do?" he contends, allows for the machine to be taken "at its mysterious face value" and prompts us to play with and explore its functionality. This project moves from asking the former question in a theoretical context, to asking the latter in the studio;

John Ellis, "Between Human and Machine: The Operating System," Journal of Contemporary Archaeology 2, no. 1 (2015), 24.

68. Tara Rodgers, Pink Noises: Women on Electronic Music and Sound (Durham and London: Duke University Press, 2010), 2-3. $\doteq$

69. Wolfgang Ernst, "Radical Media Archaeology (its Epistemology, Aesthetics and Case Studies," "Media Archaeology", coordinated by Pau Alsina, Ana Rodríguez and Vanina Y. Hofman, Artnodes no. 21 (2018): 35-43, 37. $\subseteq$

70. Garnet Hertz and Jussi Parikka, "Zombie Media: Circuit Bending Media Archaeology into an Art Method," Leonardo 45. No. 5 (2012), 426.

71. Ibid. $\triangleq$

72. Erin Striff, “Bodies of Evidence: Feminist Performance Art," Critical Survey 9, no. 1: 1-18 (1997): 1.

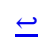

73. British Pathé, “Machine Made Voices! (1939)," April 13, 2014, accessed February 28, 2020, https://www.youtube.com/watch?v=Rld73C5Rfh4, 00:07

74. Anne Beetem Acker, "Talk box," In The Grove Dictionary of Musical Instruments (2nd Edition, Oxford University Press, 2014), accessed March 15 2020.

75. Anne Carson, "The Gender of Sound," in Audio Culture: Readings in Modern Music, Revised Edition, ed. Christoph Cox and Daniel Warner (New York: Bloomsbury Academic, 2017), $52 . \Leftarrow$

76. Ibid. $\triangleq$

77. Ibid.

78. Nina Sun Eidsheim, Sensing Sound: Singing \& Listening as Vibrational Practice (Durham: Duke University Press, 2015).

79. Ibid. $\subseteq$ 
80. Ibid.

81. Roselee Goldberg, Laurie Anderson (London: Thames and Hudson, 2000), $58 . \boxminus$

82. Cathy Lane, "Women as Animal, Women as Alien: Reclaiming Women's Demonic

Voices," in Grounds for Possible Music: On Gender, Voice, Language and Identity, ed. Julia Eckhardt (Berlin: Errant Bodies Press, 2018), $100-101 . \unlhd$

83.

Frances Dyson, "The Genealogy of the Radio Voice," in Radio Rethink: Art Sound and Transmission, ed. Diana Augaitis and Dan Lander (Banff: Walter Phillips Gallery, 1994), 167;

Lane, "Women as Animal, Women as Alien," 101.

84. Lane, "Women as Animal, Women as Alien," 101. $\subseteq$

85. Nina Power, "Woman Machines: the Future of Female Noise," in Noise E Capitalism, ed. Mattin Iles and Anthony Iles (Arteleku Audiolab, 2009), 98.

86. Dyson, "The Genealogy of the Radio Voice," 18. $\subseteq$

87. Harraway, "A Cyborg Manifesto," 141.

88. VintageCG, "VODER (1939) - Early Speech Synthesizer," April 4, 2011, accessed November 20, 2019, https://www.youtube.com/watch?v=0rAyrmm7vv0.

89. Dyson, "The Genealogy of the Radio Voice," 72.

90. Jacques Derrida, “Voice II," in Points: Interviews 1976-1994, trans. Verena Andermatt Conley

(Stanford: Stanford University Press, [1992] 1995), 161.

91. Freya Jarman-Ivens, Queer Voices: Technologies, Vocalities, and the Musical Flaw (New York:

Palgrave Macmillan, 2011), $3 . \subseteq$

92. Ibid., 15-16.

93. Ibid., 14.

94. Ibid., 12, 91 .

95. Ibid., 21.

96. Ibid., 89. 
97. Sandra Beate Reimann, "Méta-Harmony: Music Machines and Machine Music," in Jean Tinguely's Oeuvre. (Basel: Museum Tinguely \& Kerber Art, 2016), 27. $\doteq$

98.

AT\&T Tech Channel, “AT\&T Archives”;

British Pathé, “Machine Made Voices! (1939)," 00:09.

99.

Hermes Negrão, “THE RELUCTANT DRAGON by Walt Disney Sonovox,” February 25, 2009, accessed December 11, 2019, https://www.youtube.com/watch?v=blhqeWpwwkA;

British Pathé, "Sewing Machines - Old and New (1960)," April 13, 2014, accessed December 20, 2019, https://www.youtube.com/watch?v=paX-gwtSTIM\&t=5s.

100. British Pathé, "Sewing Machines," 00:08.

101. Rodgers, Pink Noises, 27. $\uplus$

102. Ibid. $\subseteq$

103. Eidsheim, Sensing Sound, 32.

104. Harraway, “A Cyborg Manifesto," 130.

105. Ibid., 143.

106. Rahm and Skågeby, "What is Feminist Media Archaeology?," 13.

107. Angela McFarlane and Helen Thornham, "Articulating Technology and Imagining the User: Generating Gendered Divides across Media," inRenewing Feminisms: Radical Narratives, Fantasies and Futures in Media Studies, ed. Helen Thornham and Elke Weissmann (I. B. Tauris \& Company, Ltd, 2013), 185.

108. Rahm and Skågeby, "What is Feminist Media Archaeology?" 13. 109. 
Research undertaken by Julia Eckhardt and Leen De Graeve demonstrates that live musicians are very often conscious of their gender expression while performing, and necessarily consider this aspect of how they will be perceived on stage. Hence, in and outside of explicitly feminist contexts, choices are commonly made by musicians and performing sound artists to either affirm or challenge gender stereotypes, and to utilise or disguise gender in performance;

Julia Eckhardt and Leen De Graeve, The Second Sound: Conversations on Gender and Music (Gent: Umland Editions 2015), 77-80.

110. Luigi Russolo, The Art of Noise: Futurist Manifesto, trans. Robert Filliou (UbuClassics, [1913] 2004), 5.

111. Ibid., 12.

112.

The phrase ‘Global South' generally refers to countries in Asia, Latin America, Africa and Oceania which are mostly, but not entirely, economically, politically or culturally marginalised. I use this term here for lack of a widely understood improved alternative. However, I also wish to problematise the term 'Global South' for its homogenising effect and geographical determinism. The same can be said for my generalised use of the term Western to denote, but generalise, the intersections of my personal privilege;

Nour Dados and Raewyn Connell, “The Global South” in Contexts 11, no. 1 (winter 2012): 12. 113. Beth Coleman, "Race as Technology," in Camera Obscura: Feminism, Culture, and Media Studies 24 , no. 1 (January 1, 2009): 177. $\subseteq$

114. Ibid., 178. $ヒ$

115. Mika Hannula, Juha Suoranta, Tere Vadén. Artistic Research Methodology: Narrative, Power and the Public (New York: Peter Lang Publishing Inc, 2014), 19. $ヒ$

116. Ibid. $\triangleq$ 